Original Research Paper

\title{
Website Usability Evaluation of Nonprofit Organizations: An Exploratory Study of Saudi Arabia
}

\author{
Saqib Saeed \\ Department of Computer Information Systems, College of Computer Science and Information Technology, Imam Abdulrahman \\ Bin Faisal University, P.O. Box 1982, Dammam, Saudi Arabia
}

\section{Article history}

Received: 14-01-2019

Revised: 08-03-2019

Accepted: 12-03-2019

Email: sbsaed@iau.edu.sa

\begin{abstract}
Community informatics discourse can be termed as a computing community's response to the social responsibility initiative, which is looking at the technological support to improve communities. Nonprofit organizations are an important part of any society, so recently there are many studies on technologically supporting this segment of society. Saudi Arabia has a huge presence of nonprofit organizations, so in the study, we have evaluated the websites of Saudi nonprofit organizations in a usability evaluation experiment. The subjects were split into two group and each group contained 21 subjects. The data was collected using questionnaire which was later analyzed to understand the design problems on the websites. The findings suggest that understudy websites of nonprofit organizations have some usability issues in navigation support, content, user interface elements consistency, the presence of error and help features. In order to effectively benefit from their websites, these organizations need to improve the website design to foster better usage by the end users.
\end{abstract}

Keywords: Nonprofit Organizations, Usability Evaluation, Human Computer Interaction, Technology Management, User Interface Design

\section{Introduction}

Nonprofit organizations are an important sector of any society which work to support underprivileged segments in society. They play their part by advocacy, lobbying and community support initiatives. As the modern government structures are moving away from the welfare system, the importance of such organizations has increased to protect the rights of the public. Technology adoption has helped governmental and business organizations in achieving organizational efficiency, but such technological advancements are not visible in the organizational settings of the nonprofit sector. Technology design in nonprofit organizations is a complex phenomenon, due to lack of funding, IT infrastructure and long-term technology policy (Saeed and Rohde, 2013; Saeed, 2014). As a result, a new discourse in computing literature has emerged which is termed as community informatics, that is aiming to improve information and community technology usage by communities (Gurstein, 1999). Seeing the limited technological adoption by nonprofit organizations, researchers' community has felt their social responsibility and are collaborating with this important sector to empower them with sustainable technological systems. So, there is an enhanced focus on nonprofit organizations to support the technological embeddedness in their organizational processes.

Saudi Arabia is a vibrant society which actively takes part in philanthropic activities and there is a huge presence of nonprofit organizations working to support humanity at local and global level (http://www.arabnews.com/node/1292101/business-

economy). With an enhanced focus on the vision 2030 program, the government is striving hard to raise the quality of life of citizens, so the role of the nonprofit sector has become very crucial. In order to connect with public, websites are becoming a vital tool and a welldesigned website can attract more volunteers and followers in the campaigns of nonprofit organizations. There is a body of literature which has looked at the usage of technology by nonprofit organizations and its impact on their functioning (Muktar et al., 2018; Cammaerts, 2017; Tadic et al., 2016; Cardoso and Neto, 2004; Saeed et al., 2011). Kang and Norton have looked at website use of nonprofit organizations and discussed how they can improve their use of websites to achieve organizational goals (Kang and Norton, 2004). Recently, the huge popularity of web 2.0 motivated many researchers to investigate the role of social media in 
improving the organizational effectiveness of nonprofit organizations (Guo and Saxton, 2018; Sun and Asencio, 2018; Wulf et al., 2013; Curtis et al., 2010; Williams et al., 2018). However, there is a little body of knowledge focusing on designing an appropriate system for nonprofit organizations.

Trigg has carried out a database redesign project for a nonprofit organization which helped them in their information management tasks (Trigg, 2000). Similarly, Farooq et al. (2005) have worked with a small nonprofit organization in Pennsylvania to design sustainable technology solutions for them. Rohde helped a network of Iranian non-governmental organizations by technologically supporting them to foster a community (Rohde, 2004). Shamail et al. (2003) have shared their experience of designing a web portal to enhance the performance of social organizations. Saeed et al. (2011) have looked at a network of social activists to chalk out technological requirements to better support them with technological interventions. Harmon et al. (2017) have carried out a rigorous study to highlight the present situation and future course of action to technologically support philanthropic activities. de Carvalho et al. (2017), have highlighted how technological infrastructures play a critical role in organizing nomadic events of social activists.

Usability is an important attribute of technological artifacts and there are many studies in literature exploring the usability issues in different technological systems (Aykin, 2016). In the health domain, Brown and Kim have analyzed the usability issues in applications supporting Alzheimer's patients and presented a set of guidelines to help designers in building better applications (Brown and Kim, 2018). Soares (2018) has carried out a comparative usability study of two ultrasound equipment used by healthcare professionals. In the context of e-learning, Ventayen et al. (2018) have looked at usability issues in Google classroom (GSuite) and concluded that this learning management system is recommended by respondents. Correa et al. (2018) have developed an educational game for visually impaired users and found it very effective in educational activities. Kumar and Mohite (2018) have critically evaluated the literature on the usability of mobile learning applications and outlined research gaps in this discourse. Amin and Saeed (2015) have investigated usability issues in OWASP WebGoat learning management system and outlined user interface improvements. Konradt et al. (2012) have concluded that usability is an important factor in the adoption of business commercial systems. Saeed (2019) has looked at the role of customer segmentation in adopting digital business by end users. There are also many studies investigating the usability of web applications in different domains to enrich this body of knowledge by documenting usability problems (Saeed et al., 2012; 2013; Saeed and Amjad, 2013).
In the context of usability of the nonprofit organization, Saeed and Shabbir have investigated the websites of Pakistani nonprofit organizations and found many design issues in those websites (Saeed and Shabbir, 2014). Despite these studies, there is not a huge body of knowledge looking into the technology usage practices in a nonprofit organization in Saudi Arabia. Keeping this in view, we are looking at the websites of nonprofit organizations in Saudi Arabia to evaluate their usability. The findings from this study will help in chalking out better design guidelines for nonprofit organizations.

Rest of the paper is structured as follows. Section 2 discusses the research methodology and in section 3 results are discussed followed by discussion and conclusion in section 4 and 5 respectively.

\section{Materials and Methods}

In this paper, we are explaining the results of our analysis of websites of nonprofit organizations in Saudi Arabia. The approach adopted in this study was crosssectional, where we collected data only once to understand the usability problems in those websites. In order to collect the data for our study, we carried out an experimental activity based on expert evaluation for data collection (Rosenbaum, 1989). The subjects for our study were identified using convenience sampling and we administered the data collection using collective administration approach where our captive audiences were enrolled students of a Human Computer Interaction class. Our selection of subjects was also influenced by the fact that these students were expert in usability evaluation and they conducted different expert and heuristic evaluation activities during the course and towards the completion of the course they participated in this study. We used split half approach and subjects were divided into two groups, each group included 21 subjects. In a lab session of the course, each group of the subjects was asked to look at the websites of two different nonprofit organization critically and they were asked to fill out a questionnaire to record their responses. This questionnaire was very comprehensive and was derived from consulting many different questionnaires proposed in the usability engineering literature (Usability questionnaires available at http:/garyperlman.com/quest/ last). The questionnaire was also reviewed by a colleague to carry out content validity and it received a positive rating. The questions in the questionnaire can be organized into five sections namely, consistency, content, navigation, error and help. There was a total of 50 questions having a rating based on a Likert scale ranging from Strongly Agree, Agree, Neutral, Disagree, Strongly Disagree $(5,4,3,2,1)$. Later the data was analyzed using statistical means. 


\section{Results}

In this section, we discuss the findings from our study. Each subsection discusses the findings associated with that part of the questionnaires.

\section{Navigation}

The logical organization of content on the website is the basis for building an effective website. In our questionnaire, there were nine questions covering the navigation related aspects. In our first question, we asked from our subjects whether the links were working fine on the website or not. We found that for group 1, 10 respondents strongly agreed, 3 agreed, 7 remained neutral and 1 respondent disagreed, however, in the group 2, 4 respondents strongly agreed, 3 agreed, 6 remained neutral, 5 disagreed and 3 strongly disagreed to the fact that all links were working correctly. This meant that group 1 websites links were working better than the group2, as evident by Table1. The second question was focused on the appropriateness and reliability of all external page links. The values in Table 1, highlight that responses of both groups converge for this question, highlighted by a value of 0.89 , of Pearson $r$ correlation factor. The third question focused on navigational effectiveness within the website and the fourth question was about the absence of any misleading link on the website. The results in Table 1, highlight that both groups have almost similar response that this aspect was handled well in the websites. The questions 5 and 6 were about the disappearance of menus during navigation and presence of orphan pages on the website, so it was expected that these questions will have a minimum rating, but the results highlight that the average value is around 2.6 for both questions meaning there is a need to improve these aspects in these websites. In the last three questions, we mainly wanted to know the accuracy of sitemap, navigation to the homepage from each page and navigation up and down within a page. It was found that sitemap features were better in group 2 websites rather than group 1, navigation from back to home feature was present optimally in both groups however navigation within page required improvements, as shown in Table 1.

It can be observed from Table 1, that except question 5 , there is a positive linear relation in the responses of both the groups. Figure 1, highlights the average and variance for each of the question responses and it can be observed that in an idealistic situation question 5 and 6 average should have approached to zero and in the other questions it should have been towards the top, but we can observe that question 1 and question 9 averages are significantly low and for question 5 and 6 it is in middle, so there is a need to improve design aspects regarding these four key aspects.

Table 1: Responses for navigation related questions

\begin{tabular}{lllllllllll}
\hline & & Q1 & Q2 & Q3 & Q4 & Q5 & Q6 & Q7 & Q8 & Q9 \\
\hline Group 1 & Strongly Agree & 10 & 12 & 14 & 16 & 3 & 3 & 4 & 13 & 4 \\
& Agree & 3 & 9 & 6 & 5 & 5 & 2 & 4 & 5 & 6 \\
& Neutral & 7 & 0 & 1 & 0 & 1 & 4 & 3 & 0 & 5 \\
& Disagree & 0 & 0 & 0 & 0 & 3 & 4 & 2 & 2 & 1 \\
& Strongly Disagree & 1 & 0 & 0 & 0 & 9 & 8 & 8 & 1 & 5 \\
Group 2 & Strongly Agree & 4 & 10 & 12 & 11 & 4 & 4 & 9 & 15 & 9 \\
& Agree & 3 & 5 & 5 & 6 & 3 & 6 & 2 & 3 & 6 \\
& Neutral & 6 & 3 & 2 & 0 & 4 & 3 & 1 & 1 & 3 \\
& Disagree & 5 & 3 & 1 & 2 & 6 & 2 & 1 & 0 & 0 \\
Pearson R & Strongly Disagree & 3 & 0 & 1 & 2 & 4 & 6 & 8 & 2 & 3 \\
& & 0.26 & 0.89 & 1.00 & 0.97 & -0.24 & 0.23 & 0.69 & 0.96 & 0.52 \\
\hline
\end{tabular}

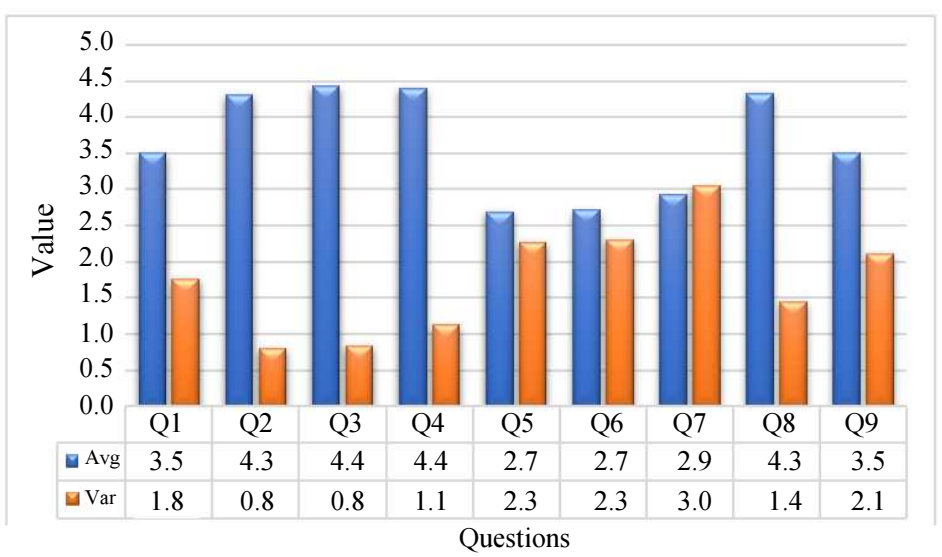

Fig. 1: Average and variance of navigation related questions 


\section{Consistency}

In our questionnaire, there were 14 questions regarding the consistency aspects in websites. In the first question, 4 respondents strongly agreed that internal search was effective, 4 agreed, 2 remained neutral, 6 disagreed and 5 strongly disagreed from group 1, however, in group 2, 15 respondents strongly agreed, 4 agreed, 1 remained neutral and 1 strongly disagreed to this fact. In the second question, most of the respondents in both groups disagreed that they observed any language inconsistency in the user interface. In the third question, most of the respondents agreed that there were format consistencies in the websites under evaluation. For question 4, in group 1, 6 respondents strongly agreed, 12 agreed, 2 remained neutral and 1 disagreed that figures and tables are aligned correctly in the website. In group 2, 11 strongly agreed, 6 agreed, 2 remained neutral, 1 disagreed and 1 strongly disagreed to the fact that figures and tables are aligned correctly in the website. In question 5 and 6, font style and font size inconsistencies were inquired respectively. From group 1, 11 respondents strongly agreed, 7 agreed, 3 remained neutral, whereas in group 2, 9 respondents strongly disagreed, 7 agreed, 1 remained neutral, 2 disagreed and 2 strongly disagreed that the websites have consistent font styles. In terms of font size, 5 respondents strongly agreed, 9 agreed, 5 remained neutral and 2 disagreed whereas from group 2,5 respondents strongly agreed, 5 agreed, 4 remained neutral, 4 disagreed and 3 strongly disagreed that consistently appropriate font sizes were present in the websites. Simplistic layout helps the user to carry out their tasks efficiently, in group 1,8 respondents strongly agreed, 5 agreed, 8 were neutral and in group 2, 8 strongly agreed, 11 agreed and 2 remained neutral about the fact that websites had a simple layout. In response to the question that whether familiar icons are being employed on the website or not, 11 respondents strongly agreed, 7 agreed, 1 remained neutral, 1 disagreed and 1 strongly disagreed from group 1, whereas in group 2, 9 respondents strongly agreed, 6 agreed, 4 remained neutral and 2 disagreed. While answering question 9, 8 respondents from group 1, strongly agreed, 7 agreed, 2 were neutral, 1 disagreed and 3 disagreed from group 1 and in group 2, 4 respondents strongly agreed, 10 agreed, 2 were neutral, 3 disagreed and 2 strongly disagreed that icons were labeled on the websites. Consistency in color fosters a pleasant user experience for end users. So, in question 10 , from group 1, 10 respondents strongly agreed, 5 agreed, 5 were neutral and 1 disagreed whereas from group 2, 15 respondents strongly agreed, 4 agreed, 1 was neutral and 1 disagreed that websites under study had consistent colors across the website. Question 11 was about consistency of menu design and from group 1, 12 respondents strongly agreed, 8 agreed and 1 respondent was neutral and in group 2, 13 respondents strongly agreed, 4 agreed, 2 were neutral, 1 disagreed and 1 strongly disagreed to the fact that menu design was consistent across the website. In response to question 12 , from group 1, 14 respondents strongly agreed, 4 agreed, 2 , remained neutral and 1 disagreed whereas from group 2, 15 respondents strongly agreed, 2 agreed, 2 disagreed and 2 strongly disagreed that menus become highlighted when selected, thus giving a clear indication of the selected option. In response to the appropriate choice of colors, from group 1, 8 respondents strongly agreed, 11 agreed, 1 remained neutral and 1 disagreed that websites have appropriate color balance. On the other hand, in group 2, 14 respondents strongly agreed, 2 agreed and 5 remained neutral. In the last question of this section, we asked for the consistent alignment of headers on each page and most of the respondents strongly agreed that the websites have consistent alignment of header throughout the website.

Pearson $r$ values in Table 2, highlight that except questions 1 , there exists a positive linear relationship in the responses of both groups. The average and variance of all 14 questions related to the consistency aspect are shown in Fig. 2. It is evident from this figure that question 1, 6 and 9 have average values below four, so there is a clear need to make internal search features more effective, consistency in font size and consistency in labeling the icons.

Table 2: Responses for consistency related questions

\begin{tabular}{llllllllllllllll}
\hline & & Q1 & Q2 & Q3 & Q4 & Q5 & Q6 & Q7 & Q8 & Q9 & Q10 & Q11 & Q12 & Q13 & Q14 \\
\hline Group 1 & Strongly Agree & 4 & 2 & 12 & 6 & 11 & 5 & 8 & 11 & 8 & 10 & 12 & 14 & 8 & 10 \\
& Agree & 4 & 3 & 7 & 12 & 7 & 9 & 5 & 7 & 7 & 5 & 8 & 4 & 11 & 8 \\
& Neutral & 2 & 0 & 2 & 2 & 3 & 5 & 8 & 1 & 2 & 5 & 1 & 2 & 1 & 2 \\
& Disagree & 6 & 3 & 0 & 1 & 0 & 2 & 0 & 1 & 1 & 1 & 0 & 1 & 1 & 1 \\
& Strongly Disagree & 5 & 13 & 0 & 0 & 0 & 0 & 0 & 1 & 3 & 0 & 0 & 0 & 0 & 0 \\
Group 2 & Strongly Agree & 15 & 4 & 10 & 11 & 9 & 5 & 8 & 9 & 4 & 15 & 13 & 15 & 14 & 16 \\
& Agree & 4 & 2 & 9 & 6 & 7 & 5 & 11 & 6 & 10 & 4 & 4 & 2 & 2 & 3 \\
& Neutral & 1 & 7 & 1 & 2 & 1 & 4 & 2 & 4 & 2 & 1 & 2 & 0 & 5 & 1 \\
& Disagree & 0 & 1 & 1 & 1 & 2 & 4 & 0 & 2 & 3 & 1 & 1 & 2 & 0 & 1 \\
& Strongly Disagree & 1 & 7 & 0 & 1 & 2 & 3 & 0 & 0 & 2 & 0 & 1 & 2 & 0 & 0 \\
Pearson R & & -0.14 & 0.35 & 0.95 & 0.64 & 0.92 & 0.86 & 0.58 & 0.91 & 0.64 & 0.89 & 0.91 & 0.95 & 0.44 & 0.82 \\
\hline
\end{tabular}




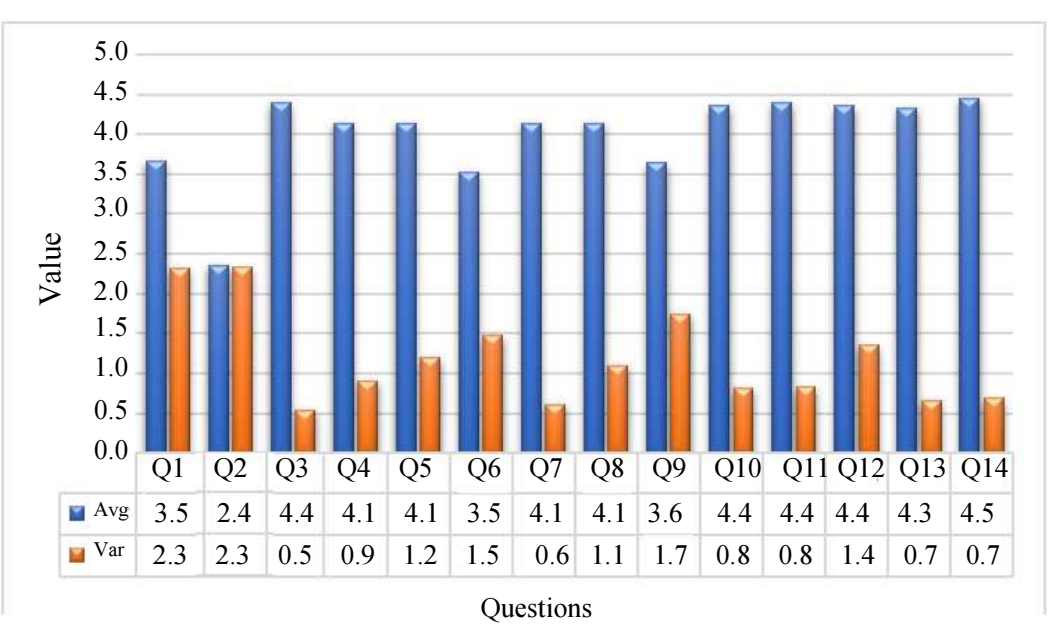

Fig. 2: Average and Variance of Consistency Related Questions

\section{Content}

In the content section of the questionnaire, we asked ten questions from the respondents. The first question was whether the pages have appropriate headings or not, so from group 1, 9 respondents strongly agreed, 7 agreed, 5 remained neutral and from the group 2, 12 respondents strongly agreed, 7 agreed and 2 disagreed. The second question was about the quality of images on the website. From group 1, 11 respondents strongly agreed, 9 agreed and 1 remained neutral whereas from group 2, 11 respondents strongly agreed, 6 agreed, 2 remained neutral, 1 disagreed and 1 strongly disagreed to the fact that images on the websites have good quality. Question 3 asked from respondents that whether headings were user-friendly and intuitive or not. From group 1, 10 respondents strongly agreed, 8 agreed, 3 remained neutral and from group 2, 11 respondents strongly agreed, 7 agreed, 1 remained neutral, 1 disagreed and 1 strongly disagreed that websites had an intuitive and user-friendly heading. Furthermore, in response to question 4 , most respondents agreed that headings were task-based.

Question 5 and 6 were about the text clarity and technicality of terms being used on the website, respectively. In both groups majority of the respondents agreed that the text was generally clear and level of technical terms was appropriate for the audience. Question 7 asked for the multilingual support on the website and from group 1, 3 respondents strongly agreed, 8 agreed, 3 remained neutral, 1 disagreed and 6 strongly disagreed and from group 2, 13 respondents strongly agreed, 2 agreed, 3 remained neutral, 1 disagreed and 2 strongly disagreed that the multilingual support was present on the websites under study. In question 8,12 respondents strongly agreed, 8 agreed, 1 remained neutral and from group 2, 7 strongly agreed, 6 agreed, 3 remained neutral and 5 disagreed that the current information was available on the websites. In the 9th question, we asked about the completeness of information on the websites. From group 1, 7 respondents strongly agreed, 10 agreed, 3 remained neutral and 1 disagreed from the group 1, whereas from group 2, 9 strongly disagreed, 7 agreed, 3 remained neutral and 1 agreed and 1 strongly disagreed that the information is complete on the websites. In the last question, we asked whether respondents observed some empty pages on the websites or not and most of the respondents disagreed that the websites contained empty pages.

It can be observed that except responses for question 7 there is a positive relationship in the responses of both groups. Figure 3 highlights that average response for question 7 , where we inquired about presence of foreign language support is weaker and similarly in question 10 where we asked for the presence of pages with empty content should reach to minimum, however, value still had an average of 1.7 highlighting that there were some pages with empty content. Pearson $r$ values, shown in Table 3 highlight that only question 7 has a negative value whereas responses of all other questions have positive value.

\section{Errors}

The absence of errors is another important characteristic of highly usable systems. In our questionnaire, we had 7 questions related to the presence of errors on the websites. In the first question, we asked from respondents whether any misspellings of words in the website were observed or not. From group 1, 14 respondents strongly disagreed, 5agreed, 1 remained neutral and 1 agreed that there were some misspellings on the websites. On the other hand, from group 2,8 respondents strongly disagreed, 4 disagreed, 2 remained neutral, 4 agreed and 3 strongly agreed that there was the presence of spelling errors on the website. In the 2nd question, we asked about the presence of grammar errors in 
the contents of websites. In group 1, 1 respondent agreed, 3 remained neutral, 4 disagreed and 13 strongly disagreed, whereas, from group 2, 1respondent strongly agreed, 3 agreed, 3 remained neutral, 7 disagreed and 7 strongly disagreed that the websites contained grammatical errors. The third question was about the presence of punctuation errors on the websites and from group1, 1 respondent agreed, 3 remained neutral, 4 disagreed and 13 strongly disagreed that the websites had punctuation errors. From group 2, 1 respondent strongly agreed, 3 agreed, 3 remained neutral, 7 disagreed and 7 strongly disagreed to the fact that websites had punctuation errors. In the fourth question, we enquired about the order of the information and most of the respondents agreed that information is well structured logically and not just placed in alphabetical order. In the 5 th question, a large proportion of respondents from both groups strongly agreed that headings within page were labeled correctly. Question 6 and 7, inquired about the presence of at least one heading per page and heading reflecting the content appropriately, respectively. In both questions, most of the respondents agreed to the fact that at least there was one heading on each page and heading titles were reflecting the content properly.

It can be deduced from Table 4, that all the questions have a strong linear relationship among the responses of all questions. Figure 4, highlights that question 1-4 have a lower average value, these questions were related to the presence of grammar, punctuation, spelling and ordering errors where the intended outcome was nearing lower bound, which highlights that there is need to fix these errors in these websites.

\section{Help}

Providing help to users is another important characteristic of a highly usable system. This helps novice users to get their tasks done effectively. In our questionnaire, we asked ten questions. In the first question, we asked whether there was a possibility of getting feedback and asking questions was enabled on the websites.

Table 3: Responses for content related questions

\begin{tabular}{|c|c|c|c|c|c|c|c|c|c|c|c|}
\hline & & Q1 & Q2 & Q3 & Q4 & Q5 & Q6 & Q7 & Q8 & Q9 & Q10 \\
\hline \multirow[t]{5}{*}{ Group 1} & Strongly Agree & 9 & 11 & 10 & 6 & 8 & 10 & 3 & 12 & 7 & 1 \\
\hline & Agree & 7 & 9 & 8 & 6 & 8 & 5 & 8 & 8 & 10 & 0 \\
\hline & Neutral & 5 & 1 & 3 & 8 & 5 & 6 & 3 & 1 & 3 & 2 \\
\hline & Disagree & 0 & 0 & 0 & 0 & 0 & 0 & 1 & 0 & 1 & 5 \\
\hline & Strongly Disagree & 0 & 0 & 0 & 1 & 0 & 0 & 6 & 0 & 0 & 13 \\
\hline \multirow[t]{5}{*}{ Group 2} & Strongly Agree & 12 & 11 & 11 & 11 & 10 & 8 & 13 & 7 & 9 & 1 \\
\hline & Agree & 7 & 6 & 7 & 5 & 7 & 9 & 2 & 6 & 7 & 2 \\
\hline & Neutral & 0 & 2 & 1 & 4 & 2 & 3 & 3 & 3 & 3 & 1 \\
\hline & Disagree & 2 & 1 & 1 & 0 & 2 & 1 & 1 & 5 & 1 & 5 \\
\hline & Strongly Disagree & 0 & 1 & 1 & 1 & 0 & 0 & 2 & 0 & 1 & 12 \\
\hline Pearson $\mathrm{R}$ & & 0.81 & 0.96 & 0.95 & 0.68 & 0.87 & 0.79 & -0.20 & 0.77 & 0.90 & 0.98 \\
\hline
\end{tabular}

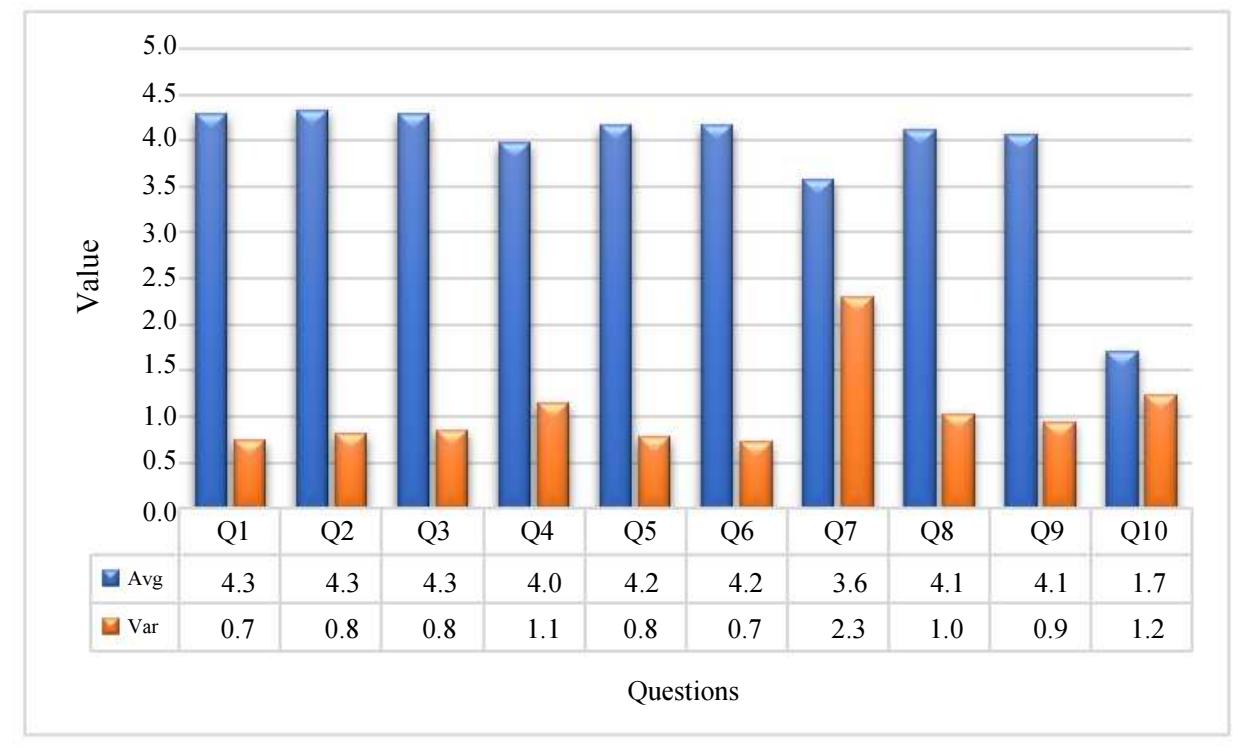

Fig. 3: Average and variance of content related questions 
In group 1, 4 respondents strongly agreed, 6 agreed, 8 remained neutral, 3 strongly disagreed and from group 2, 14 respondents strongly agreed, 1 agreed, 2 remained neutral, 1 disagreed and 3 strongly disagreed to the fact that websites had enabled the possibility of providing feedback. Question 2 was about the simplicity of the domain name and majority of respondents agreed that the websites had a simplistic domain name. In question 3 , we asked about the presence of contact information like phone number, fax number, email and postal address on the website. From group 1, 1 respondent strongly agreed, 5 agreed, 6 disagreed and 9 strongly disagreed whereas from group 2, 8 respondents strongly agreed, 2 agreed, 2 remained neutral, 4 disagreed and 5 strongly disagreed that websites had contact information posted on the websites under study. In questions 4, we asked whether help feature was enabled on the website or not. In group 1, 5 respondents strongly agreed, 3 agreed, 4 remained neutral, 3 disagreed and 6 strongly disagreed that help feature was present on the websites. In group 2, 8 respondents strongly agreed, 2 remained neutral, 4 agreed and 7 strongly disagreed that the help feature was enabled on the websites. In question 5, from group 1, 3 respondents strongly agreed, 5 agreed, 1 remained neutral, 2 disagreed and 10 strongly disagreed, whereas from group 2, 10 respondents strongly agreed, 3 agreed and 8 strongly disagreed that sitemap was present on the websites. In question 6 , most of the respondents agreed that homepage contained subheadings which were self-explanatory. Question 7 was about the presence of search tool on the website where from group 1, 8 respondents strongly agreed, 1 agreed, 2 remained neutral, 4 disagreed and 6 strongly disagreed and from group 2, 18 respondents strongly agreed, 1 agreed, 1 disagreed and 1 strongly disagreed that the search tool was present on the website. Question 8 focused on users' efficiency that whether users were able to find the answers to their respective queries within 10 seconds or not.

Table 4: Responses for Error Related Questions

\begin{tabular}{lllllllll}
\hline & & Q1 & Q2 & Q3 & Q4 & Q5 & Q6 & Q7 \\
\hline Group 1 & Strongly Agree & 0 & 0 & 0 & 1 & 11 & 12 & 10 \\
& Agree & 1 & 1 & 0 & 2 & 6 & 6 & 8 \\
& Neutral & 1 & 3 & 3 & 5 & 4 & 3 & 3 \\
& Disagree & 5 & 4 & 6 & 5 & 0 & 0 & 0 \\
\multirow{5}{*}{ Group 2 } & Strongly Disagree & 14 & 13 & 12 & 8 & 0 & 0 & 0 \\
& Strongly Agree & 3 & 1 & 3 & 2 & 12 & 11 & 9 \\
& Agree & 4 & 3 & 1 & 0 & 6 & 4 & 9 \\
& Neutral & 2 & 3 & 1 & 7 & 2 & 4 & 2 \\
& Disagree & 4 & 7 & 7 & 6 & 0 & 1 & 0 \\
Pearson R & Strongly Disagree & 8 & 7 & 9 & 6 & 1 & 1 & 1 \\
\hline
\end{tabular}

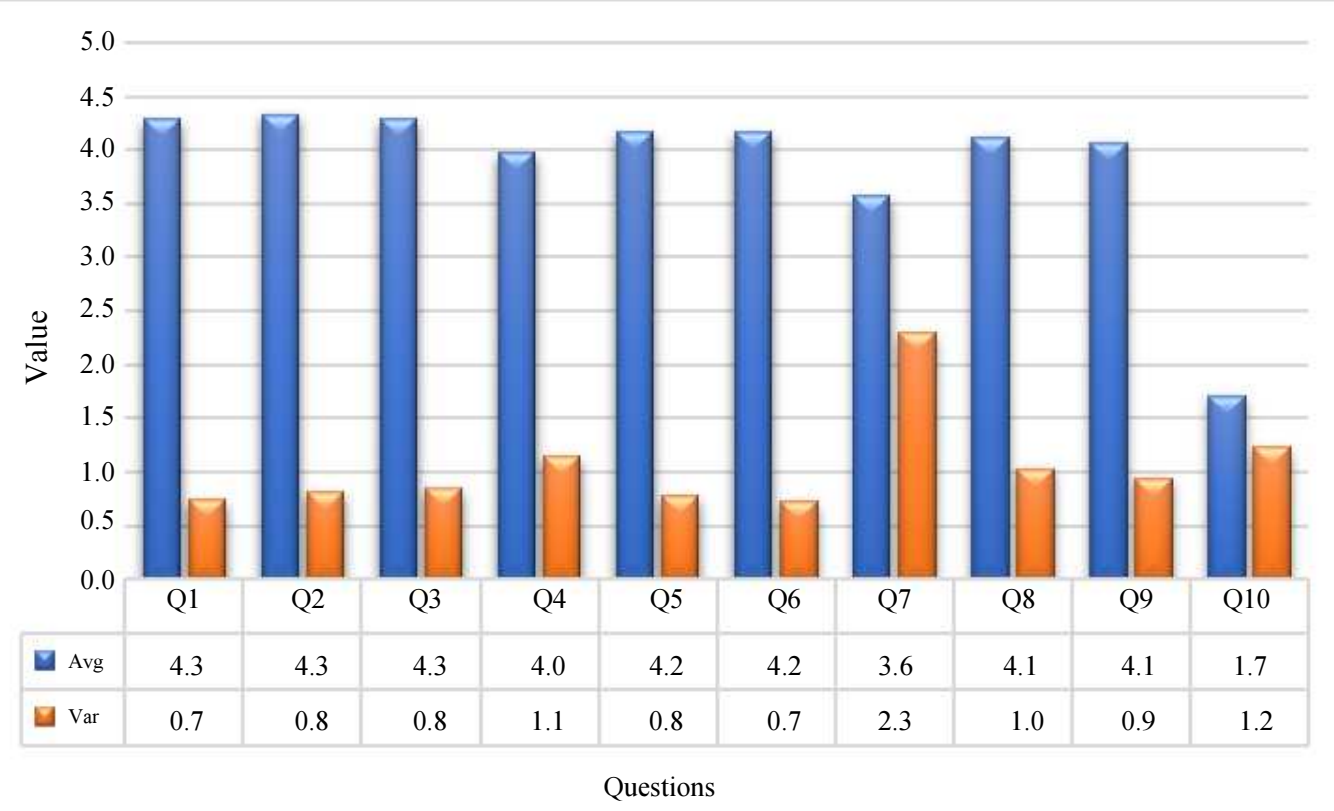

Fig. 4: Average and variance of errors related question 
From group 1, 2 respondents strongly agreed, 3 agreed, 9 remained neutral, 4 disagreed and 3 strongly disagreed and from group 2, 7 respondents strongly agreed, 6 agreed, 7 remained neutral and 1 strongly disagreed that they were able to find the answer of their questions within 10 seconds. The date of the last update is an important factor in determining the validity of information on a website. In question 9 of the questionnaire, 2 respondents strongly agreed, 2 remained neutral, 5 disagreed and 12 strongly disagreed from group 1 and from group 2, 5 respondents strongly agreed, 1 agreed, 2 remained neutral, 7 disagreed and 6 strongly disagreed to the fact that they were able to find last update date on the websites. The last question was about the presence of purpose statement on each of the webpage. From group 1, 8 respondents strongly agreed, 5 agreed, 5 remained neutral, 3 disagreed and from group 2, 13 respondents strongly agreed, 3 agreed, 4 remained neutral and 1 disagreed that the purpose of each website was very clear.

Table 5, highlights that other than question 1 and 3 there is a positive correlation in the responses of questions. Figure 5, highlights that features like question facilitation, contact information, last update dates and response time were having low average ratings so nonprofit organizations need to take care of improving these aspects on their websites.

\section{Validity of Fndings}

In order to measure the internal consistency of the data, we calculated the value of Cronbach Alpha by carrying out the Anova two factor analysis without replication and the results are shown in Table 6. The value of Cronbach Alpha is 0.84 which shows a good level of internal validity.

Table 5: Responses for Help Related Questions

\begin{tabular}{llllllllllll}
\hline \multirow{6}{*}{ Group 1 } & Q1 & Q2 & Q3 & Q4 & Q5 & Q6 & Q7 & Q8 & Q9 & Q10 \\
& Strongly Agree & 4 & 9 & 1 & 5 & 3 & 9 & 8 & 2 & 2 & 8 \\
& Agree & 6 & 8 & 5 & 3 & 5 & 7 & 1 & 3 & 0 & 5 \\
& Neutral & 8 & 2 & 0 & 4 & 1 & 2 & 2 & 9 & 2 & 5 \\
& Disagree & 0 & 0 & 6 & 3 & 2 & 3 & 4 & 4 & 5 & 3 \\
Group 2 & Strongly Disagree & 3 & 2 & 9 & 6 & 10 & 0 & 6 & 3 & 12 & 0 \\
& Strongly Agree & 14 & 11 & 8 & 8 & 10 & 15 & 18 & 7 & 5 & 13 \\
& Agree & 1 & 4 & 2 & 0 & 3 & 4 & 1 & 6 & 1 & 3 \\
& Neutral & 2 & 2 & 2 & 2 & 0 & 0 & 0 & 7 & 2 & 4 \\
& Disagree & 1 & 2 & 4 & 4 & 0 & 1 & 1 & 0 & 7 & 1 \\
Pearson R & Strongly Disagree & 3 & 2 & 5 & 7 & 8 & 1 & 1 & 1 & 6 & 0 \\
& & -0.02 & 0.81 & -0.03 & 0.79 & 0.56 & 0.84 & 0.75 & 0.26 & 0.67 & 0.88 \\
\hline
\end{tabular}

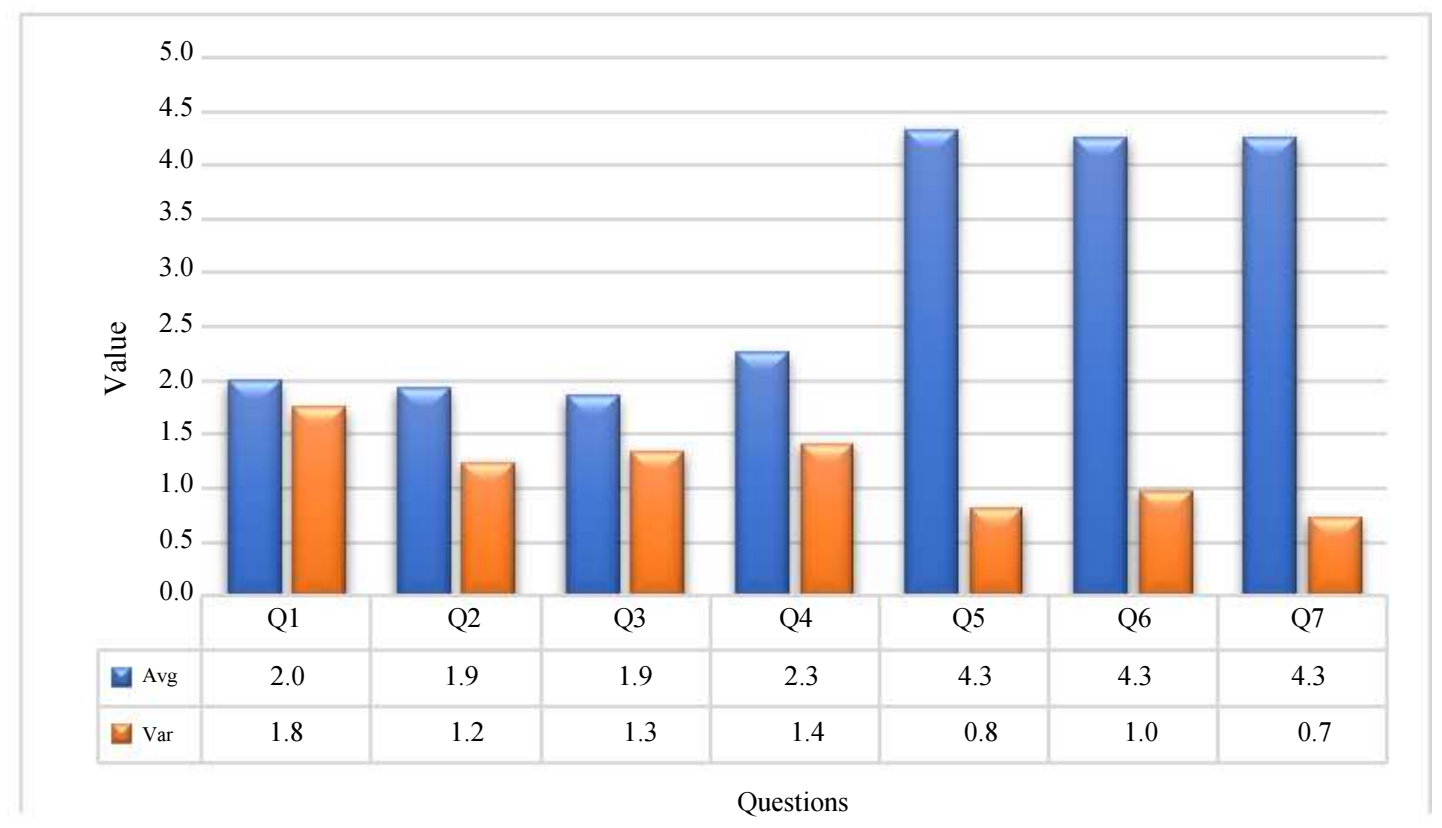

Fig. 5: Average and variance of help related questions 
Table 6: Anova analysis

\begin{tabular}{lllllll}
\hline Source of variation & SS & df & MS & F & P-value & F crit \\
\hline Rows & 333.4480952 & 41 & 8.132880372 & 6.242472995 & $1.53367 \mathrm{E}-30$ & 1.395031325 \\
Columns & 1401.514762 & 49 & 28.60234208 & 21.95401136 & $5.7439 \mathrm{E}-151$ & 1.360351729 \\
Error & 2617.385238 & 2009 & 1.302829885 & & & \\
Total & 4352.348095 & 2099 & & & & \\
\hline
\end{tabular}

\section{Discussion}

The technological revolution has transformed organizational processes but adopting technological artifacts requires well thought out strategy, resources and infrastructure. This is more problematic in the case of nonprofit organizations, due to their inherent fragile structural and financial scarcity. In this paper, we have explored the usability problems in the websites of nonprofit organizations in Saudi Arabia. The website is an effective tool for nonprofit organizations to carry out advocacy, campaigning and volunteer recruiting. A poorly designed website discourages users to actively participate in nonprofit organizations activities and a well-designed website encourages participation.

Our lab study provides deep insights into the design of these websites and our findings are in line with the earlier studies in different geographical regions (Saeed and Shabbir, 2014). It was very interesting to identify that majority of design considerations are rated positively by our subjects, however, there is still need for further improvements. In terms of navigational aspects, the websites need to further improve on inactivity of some links, presence of sitemap and navigational aspects within pages to establish a positive user experience. In terms of consistency, website designers need to look at improving internal search effectiveness, language interoperability, labeling of icons and font consistency. In terms of content multilingual support and missing content were two items where our respondent rated negatively. Regarding errors, respondents observed that language and punctuation errors were visible at some of the pages. Furthermore, respondents reported, lack of help in terms of question facilitation, missing contact information and validity of information (missing last update details).

One of the limitations of this work is that our test subjects were picked using conveyance sampling which may not be representative of the entire population, so we propose detailed follow-up quantitative and qualitative studies to enrich the body of knowledge on cultural and socio-technical implications. On the findings of these empirical studies, appropriate websites can be designed using participatory design approaches (Saeed et al., 2017). A rich documentation of such design studies may serve as foundations for developing design guidelines for websites of community organizations.

\section{Conclusion}

Nonprofit organizations are an important part of society and there is a need to technologically support them for improving their organizational effectiveness. In this study, we have carried out usability analysis of websites of some Saudi Arabian nonprofit organizations. The studies suggest that websites need further refinement in terms, of navigation, consistency, content, error prevention and help feature, to enable users to interact effectively with their websites. As this is a cross-sectional study so there is a need for future studies having a more balanced sample from all regions of Saudi Arabia and involving the users in the redesign process of these websites to foster better usage.

\section{Acknowledgement}

Author would like to thank Ms. Hina Gull and Mr. Sardar Zafar Iqbal for their support in data collection and analysis.

\section{Ethics}

This article is original and contains unpublished material. The corresponding author confirms that anonymity of respondent was ensured during data gathering and analysis.

\section{References}

Amin, M.A. and S. Saeed, 2015. Role of usability in elearning system: An empirical study of OWASP WebGoat. In Human Factors in Software Development and Design, IGI Global, pp: 295-312.

Aykin, N., 2016. Usability and internationalization of information technology. CRC Press.

Brown, J. and H.N. Kim, 2018. Usability of Alzheimer's mHealth Applications. J. Best Practices Health Professions Diversity: Education, Research Policy

Cammaerts, B., 2017. ICT-usage among transnational social movements in the networked society: To organise, to mobilise and to debate. In Media, Technology and Everyday Life in Europe, Routledge, pp: 71-90.

Cardoso, G. and P.P. Neto, 2004. Mass media driven mobilization and online protest ICTs and the pro-East Timor movement in Portugal, In: Cyber Protest, New Media, Citizens and Social Movements, van de Donk, W., B.D. Loader, P.G. Nixon and D. Rucht (Eds.), London: Routledge, pp: 147-163. 
Correa, A.G., L.C. De Biase, E.P. Lotto and R.D. Lopes, 2018. Development and usability evaluation of an configurable educational game for the visually impaired. Proceedings of the IEEE Games, Entertainment, Media Conference (GEM' 18), IEEE Xplore press, pp: 1-9.

Curtis, L., C. Edwards, K.L. Fraser, S. Gudelsky and J. Holmquist et al., 2010. Adoption of social media for public relations by nonprofit organizations. Public Relations Rev., 36: 90-92.

de Carvalho, A.F.P., S. Saeed, C. Reuter and V. Wulf, 2017. The role of technological infrastructure in nomadic practices of a social activist community. Int. Reports Socio-Informatics, 14: 41-47.

Farooq, U., C.B. Merkel, H. Nash, M.B. Rosson and J.M. Carroll et al., 2005. Participatory design as apprenticeship: Sustainable watershed management as a community computing application. Proceedings of the 38th Annual Hawaii International Conference on System Sciences (HICSS'05), IEEE Xplore press, pp: $178 \mathrm{c}-178 \mathrm{c}$.

Guo, C. and G.D. Saxton, 2018. Speaking and being heard: How nonprofit advocacy organizations gain attention on social media. Nonprofit Voluntary Sector Q., 47: 5-26.

Gurstein, M., 1999. Community informatics: Enabling communities with information and communications technologies: Enabling communities with information and communications technologies. IGI Global.

Harmon, E., C. Bopp and A. Voida, 2017. The design fictions of philanthropic IT: Stuck between an imperfect present and an impossible future. Proceedings of the CHI Conference on Human Factors in Computing Systems, ACM, pp: 7015-7028.

http://www.arabnews.com/node/1292101/businesseconomy

Kang, S. and H.E. Norton, 2004. Nonprofit organizations' use of the World Wide Web: Are they sufficiently fulfilling organizational goals? Public Relations Rev., 30: 279-284.

Konradt, U., L. Lückel and T. Ellwart, 2012. The role of usability in business-to-business e-commerce systems: Predictors and its impact on user's strain and commercial transactions. Advances HumanComputer Interaction.

Kumar, B.A. and P. Mohite, 2018. Usability of mobile learning applications: A systematic literature review. J. Computers Education, 5: 1-17.

Muktar, B.G., N. Man, J.M. Saleh and M.I. Daneji, 2018. Evaluation of ICTs access, use and preferences for livelihood resilience: Results from a survey of Malaysian fisher folks. J. Agric. Education Extension.

Rohde, M., 2004. Find what binds. Building social capital in an Iranian NGO community system. Social Capital Inform. Technol., 75: 111.
Rosenbaum, S., 1989. Usability evaluations versus usability testing: When and why? IEEE Trans. Professional Communication, 32: 210-216.

Saeed, S. and A. Amjad, 2013. Understanding usability issues of Pakistani university websites. Life Sci. J., 10: 479-482.

Saeed, S. and M. Rohde, 2013. Technology design for egovernance in nonprofit organizations. In HumanCentered System Design for Electronic Governance, IGI Global, pp: 49-58.

Saeed, S. and S. Shabbir, 2014. Website usability analysis of nonprofit organizations: A case study of Pakistan. Int. J. Public Administration Digital Age, 4: 70-83.

Saeed, S., 2014. User-centric technology design for nonprofit and civic engagements. Springer International Publishing.

Saeed, S., 2019. Digital Business adoption and customer segmentation: An exploratory study of expatriate community in Saudi Arabia. ICIC Express Lett.

Saeed, S., I. Jamshaid and S. Sikander, 2012. Usability evaluation of hospital websites in Pakistan. Int. J. Technology Diffusion, 3: 29-35.

Saeed, S., I.A. Malik and F. Wahab, 2013. Usability evaluation of Pakistani security agencies websites. Int. J. E-Politics, 4: 57-69.

Saeed, S., M. Rohde and V. Wulf, 2011. Analyzing political activists' organization practices: findings from a long term case study of the European social forum. Computer Supported Cooperative Work, 20: 265-304.

Saeed, S., M. Rohde and V. Wulf, 2011. Communicating in a transnational network of social activists: The crucial importance of mailing list usage. Proceedings of the International Conference on Collaboration and Technology (ICCT'11), Springer, Berlin, Heidelberg, pp: 81-88.

Saeed, S., Y.A. Bamarouf, T. Ramayah and S.Z. Iqbal, 2017. Design solutions for user-centric information system.

Shamail, S.H., M.M. Awais, S.H. Masud and S.A. Shams, 2003. Web based portal for capacity building of development sector enterprises in Pakistan. Proceedings of the 2nd World Scientific and Engineering Academy and Society Conference on E-Activities, Singapore.

Soares, M., 2018. Evaluation of usability of two therapeutic ultrasound equipment. Proceedings of the 20th Congress of the International Ergonomics Association (IEA'8), Springer.

Sun, R. and H.D. Asencio, 2018. Using social media to increase nonprofit organizational capacity. Int. J. Public Administration.

Tadic, B., M. Rohde, V. Wulf and D. Randall, 2016. ICT use by prominent activists in Republika Srpska. Proceedings of the 2016 CHI Conference on Human Factors in Computing Systems (HFCS'16), ACM, pp: $3364-3377$. 
Trigg, R.H., 2000. From sandbox to "Fundbox": Weaving participatory design into the fabric of a busy non-profit. Participatory Design Conference Palo Alto, CA, USA.

Usability questionnaires available at http:/garyperlman.com/quest/ last

Ventayen, R.J.M., K.L.A. Estira, M.J. De Guzman, C.M. Cabaluna and N.N. Espinosa, 2018. Usability evaluation of Google classroom: Basis for the Adaptation of GSuite E-Learning Platform. Asia Pacific J. Education Arts Sci., 5: 47-51.
Williams, B.D., J.N. Valero and K. Kim, 2018. Social media, trust and disaster: Does trust in public and nonprofit organizations explain social media use during a disaster? Quality Quantity, 52: 537-550.

Wulf, V., K. Aal, I. Abu Kteish, M. Atam and K. Schubert et al., 2013. Fighting against the wall: social media use by political activists in a Palestinian village. Proceedings of the SIGCHI Conference on Human Factors in Computing Systems (HFCS' 13), ACM, pp: 1979-1988. 